\title{
ENHANCEMENT OF CYTOTOXIC ACTIVITY BY ENCAPSULATION IN PLURONIC POLYMER MICELLES: LEPTOCARPHA RIVULARIS EXTRACTS AGAINST HUMAN CANCER CELL LINES
} \author{
ANDRÉS F. OLEA ${ }^{1 *}$, JOAN VILLENA ${ }^{2}$, ALEJANDRA MOLLER ${ }^{3}$, ROLANDO MARTÍNEZ4 HÉCTOR CARRASCO ${ }^{1 *}$ \\ ${ }^{1}$ Instituto de Ciencias Químicas Aplicadas, Facultad de Ingeniería, Universidad Autónoma de Chile, Llano Subercaseaux 2801, San \\ Miguel, Santiago,Chile.andres.olea@uautonoma.cl(AFO); hector.carrasco@uautonoma.cl (HC). \\ ${ }^{2}$ Centro de Investigaciones Biomédicas (CIB), Escuela de Medicina, Universidad de Valparaíso, Av. Hontaneda 2664 , Valparaíso \\ 234000,Chile.Juan.villena@uv.cl. \\ ${ }^{3}$ Escuela de Tecnología Médica, Universidad de Valparaíso,Angamos665, Reñaca, Chile.alejandra.moller@uv.cl. \\ ${ }^{4}$ Departamento de Química, Facultad de Ciencias Exactas, Universidad Andrés Bello, Quillota 910 , Viña del Mar 252000, Chile. \\ rmartinez@unab.cl
}

\section{ABSTRACT}

Leptocarpha rivularis is an autochthonous plant of the southern zone of Chile known as "Palo negro" that has been traditionally used by Mapuche people as antiinflammatory and reliever of abdominal pain. More recently, aqueous infusion of this plant is being used in the treatment of cancer. The main phytochemical components of $L$. rivularis have been identified as a sesquiterpene lactones (SQL) being leptocarpine (LTC) the major component, which exhibits pro-apoptotic action against a variety of cancer cells lines. In this study we intend to compare the in vitro cytotoxicity against cancer cell lines of two different polarity extracts and LTC. To overcome the poor water-solubility of extracts they have been encapsulated in polymer micelles and its effect on activity has been assessed.

The results indicate that both extracts reduce cell viability of all cancer cell lines. The $\mathrm{IC}_{50}$ values obtained for ethyl acetate are in the range of $11-16 \mu \mathrm{g} / \mathrm{mL}$, and this activity is explained in terms of a synergic effect generated by SQL different to LTC. The IC 50 values of extracts incorporated into polymer micelles formed by Pluronic F127 are 200 times lower than those measured for ethyl acetate extract applied in homogeneous solution. Finally, by assessing changes in cell and nuclear morphology it is suggested that the observed cytotoxicity of free and entrapped extracts is produced by apoptotic process. In conclusion, these results suggest that plant extracts may show an increased activity as result of synergic effect of minority components, and an important enhancement of cytotoxicity is induced by entrapment into polymer micelles.

Keywords: Cytotoxicity; plant extracts; sesquiterpene lactones; leptocarpine; apoptosis; polymer micelles.

\section{INTRODUCTION}

The application of medicinal plants (MP) in the treatment of cancer is a matter of current interest ${ }^{1,2}$, mainly because a large number of drugs with anticancer activity has been obtained from natural products ${ }^{3}$; and additionally, because MP are used worldwide as complementary and alternative medicine $(\mathrm{CAM})^{4}$. Anticancer studies of cancer drug efficiency have shown that cell death by apoptosis can be increased by inhibition of the nuclear factor kappa $\mathrm{B}(\mathrm{NF}-\mathrm{kB})^{5-10}$. Interestingly, many natural products exhibit cytotoxic activity on human cancer cell lines, which has been attributed to inhibition of this factor. For example, the biological activities of sesquiterpene lactones (SQL) have been explained in terms of NF-kB inhibition induced by the $\alpha$ methylene $\gamma$-butyrolactone group that is highly reactive $e^{11-16}$. In Figure 1 are shown the chemical structures of some active SQL: parthenolide, which has shown antitumor activity against different human cancer cells lines ${ }^{17-21}$; and cynaropicrin that exhibits cytotoxicity against leukocyte cancer cell lines (U937 and Jurkat T cells) ${ }^{22}$.
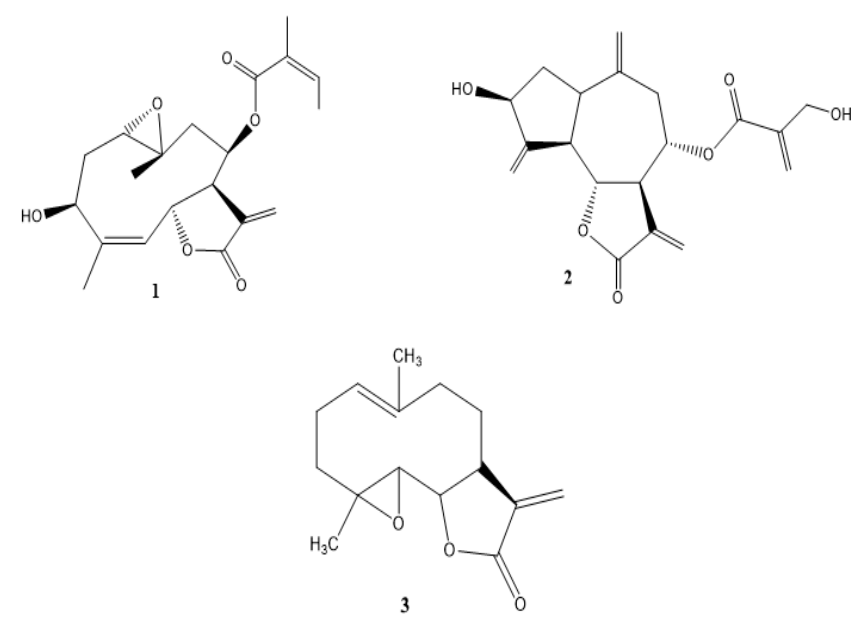

Figure 1. Chemical structures of some SQL with cytotoxic activity: (1) leptocarpin, (2) cynaropicrin, (3) parthenolide.
Leptocarpha rivularis is a shrub of the Astaracea family that grows at the southern part of Chile. This plant has been used as folk medicine by the Mapuche ethnia for the treatment of gastric ulcers. Phytochemical studies have shown that $L$. rivularis contains a high percentage of SQL, highlighting leptocarpine (LTC) as the main component $\mathrm{t}^{23,24}$. LTC has a similar structure to other active SQL (see Figure 1), and it is highly cytotoxic, induces apoptosis, and acts as an efficient inhibitor of NF- $\mathrm{KB}^{23,25}$. The concentration of LTC required to reach the levels of activity shown by parthenolide and other SQL is in the same order of magnitude. Based on these findings, LTC has been proposed as a potential therapeutic agent for treatment of $\operatorname{cancer}^{25}$.

Despite the number of known clinical activities shown by SQL the studies of plant extracts, from which active SQL are obtained, are scarce. Some studies have been mainly focused on the inhibition of NF- $\kappa B$ by extracts obtained from dietary and medicinal plants ${ }^{26-29}$. Most of these studies have been carried out with ethanolic extracts, even though active compounds are usually found in non-polar extracts, because of the low polarity of these compounds.

The poor water-solubility of natural products is the main drawback in their potential clinical development as chemotherapeutics drugs. To overcome this difficulty two different approaches have been used: incorporation of them into polymer micelles; and attaching polar or ionizable groups to the parent drug structure. The latter approach has recently been applied to develop a series of water-soluble derivatives of parthenolide $e^{30,31}$.

On the other hand, the application of polymer micelles as delivery vehicles for anti-cancer drugs has been extensively studied in the last two decades $^{32-35}$. These micelles are formed by block copolymers having blocks of different polarities. Commercial triblock copolymers, known by the trade name of Pluronic, consist of a central hydrophobic block of poly(propylene oxide) (PPO) and hydrophilic end blocks of poly(ethylene oxide) (PEO), PEO-PPO-PEO. In aqueous solution these copolymers self-aggregate at a critical micelle concentration $(\mathrm{cmc})$ forming aggregates of different morphologies. Pluronic F127 form spherical micelles with a core-shell structure where the micellar core consists of hydrophobic PPO blocks, whereas the corona is formed by hydrated PEO blocks ${ }^{36}$. The properties and potential application of these micelles as drug carriers have been extensively studied by several group $\mathrm{s}^{37-40}$. 
Thus, in this work we have evaluated the in vitro cytotoxicity of ethyl acetate and ethanol extracts of $L$. rivularis on different cancer cell lines. The extracts were applied in homogeneous solution and entrapped into polymer micelles of Pluronic F127. The results are compared with the activity that has been reported for pure LTC.

\section{EXPERIMENTAL}

\subsection{Plant collection}

Leaves and branches from L. rivularis were collected during summer season, in the environs of Valdivia $\left(39^{\circ} 47^{\prime} \mathrm{S}, 73^{\circ} 13^{\prime} \mathrm{W}\right)$, Los Rios region, southern Chile at $60 \mathrm{~m}$ altitude approximately. Plants were identified in the field by Prof. R. Martinez and a voucher specimen was deposited at the Institute of Botany of the Universidad Austral de Chile ( $n^{\circ}$ : VALD 13006).

\subsection{Plant material extraction}

Plant material was dried for two days. Then a fixed amount of grounded dry material was macerated with ethyl acetate (EA) for two days, the solvent is collected, and a new portion of EA is added. This process is repeated three times. The solid extracted material is subsequently macerated with ethanol following the same procedure described for EA. The extracts were concentrated under vacuum at $50{ }^{\circ} \mathrm{C}$, in a rotary evaporator (Buchi, Germany) and then dried in a fume hood.

\subsection{Entrapment of extracts in polymeric micelles of Pluronic F127}

Pluronic F127 (Aldrich) was used as received. Pluronic F127 is a triblock copolymer $\mathrm{PEO}_{100} \mathrm{PPO}_{65} \mathrm{PEO}_{100}$ with a molecular weight of $12,600 \mathrm{~g} / \mathrm{mol}$, and a cmc of $2.7 \mu \mathrm{M}^{41,42}$. Aqueous solutions of Pluronic F127 (1mM in a molar chain unit basis) were prepared with distilled and deionized water obtained from an EASYpure RF (Barnstead) deionization system. Extracts were entrapped into polymer micelles by using the emulsion method ${ }^{43}$. Briefly, an aliquot of extract dissolved in dichloromethane is added to an aqueous solution of Pluronic F127, and then mixed in a vortex to form an emulsion. The dichloromethane is eliminated by heating and sonication of the mixture, and the final concentration of extract is $5 \mathrm{mg} / \mathrm{mL}$.

\subsection{Cytotoxicity assays}

\subsubsection{Cell culture}

HT-29 cells (colon cancer cell line), PC-3 (prostate cancer cell lines), MCF-7 (breast cancer cell lines) and CCD $841 \mathrm{CoN}$ (human colon epithelial cells) were obtained from the American Type Culture Collection (Rockville, MD, USA). All tested cell lines were maintained in a $1: 1$ mixture of Dulbecco's modified Eagle's medium (DMEM) and Ham's F12 medium, containing $10 \%$ heat-inactivated fetal bovine serum (FBS), amphotericin $(2.5$ $\mu \mathrm{g} / \mathrm{mL})$, penicillin $(100 \mathrm{U} / \mathrm{mL})$ and streptomycin $(100 \mu \mathrm{g} / \mathrm{mL})$. Fetal bovine serum, penicillin, and streptomycin were obtained from Hyclone (Santiago, Chile) and used as received.

2.4.2 In vitro cytotoxicity screening by using sulforhodamine B $\operatorname{assay}^{44,45}$.

Stock cells were incubated at $37{ }^{\circ} \mathrm{C}$ under humid atmosphere with $5 \%$ $\mathrm{CO}_{2}$ for $24 \mathrm{~h}$ before the test. The cell suspension was set up at 3,000 cells per well of a 96-flat-bottomed $200 \mu \mathrm{L}$ well microplate. Extracts were dissolved in ethanol or aqueous solution of Pluronic F127 (1 mM) at a concentration of $5 \mathrm{mg} / \mathrm{mL}$ and diluted with the growth medium to the desired concentrations $(0-100 \mu \mathrm{g} / \mathrm{mL})$. Negative control cultures were prepared by adding just $1 \%$ ethanol or $1 \mathrm{mM}$ aqueous solution of Pluronic F 127. All culture microplates were incubated at $37{ }^{\circ} \mathrm{C}$ in a $\mathrm{CO}_{2}$ incubator with humidified $5 \% \mathrm{CO}_{2}$ for 72 $\mathrm{h}$. At the end of drug exposure, cells were fixed with $50 \%$ trichloroacetic acid at $4{ }^{\circ} \mathrm{C}$. After washing with water, cells were stained with $0.1 \%$ SRB dissolved in $1 \%$ acetic acid $(50 \mu \mathrm{L} /$ well $)$ for $30 \mathrm{~min}$, and subsequently washed with $1 \%$ acetic acid to remove unbound stain. Protein-bound stain was solubilized with $100 \mu \mathrm{L}$ of $10 \mathrm{mM}$ unbuffered Tris base, and the cell density was determined using an ELISA fluorescence plate reader at an emission wavelength of $540 \mathrm{~nm}$ using the program Gen5 1.07. The obtained data were expressed as percentages of viability cells versus solvent control, whose viability was considered $100 \%$. Values shown are the mean \pm SD of three independent experiments in triplicate. The software used to calculate the $\mathrm{IC}_{50}$ values was SigmaPlot version 11.0. Sulforhodamine B (SRB) and Pluronic F
127 were obtained from Sigma-Aldrich (St. Louis, MO, USA) and used without further purification.

\subsubsection{Morphological Assessment of Cell Apoptosis}

Cell and nuclear morphology were analyzed, after $48 \mathrm{~h}$ of treatment to different extracts $(0$ and $25 \mu \mathrm{g} / \mathrm{mL})$, using phase contrast microscopy and immune fluorescence microscopy, respectively.

Morphological changes in the nuclear chromatin of cells undergoing apoptosis were revealed by a nuclear fluorescent dye, Hoechst 33342. Briefly, CCD 841 CoN, HT-29, PC-3 and MCF-7 $\left(1 \times 10^{4}\right.$ cells $\left./ \mathrm{mL}\right)$ were cultured on 24-well chamber slides, and exposed to compounds for $48 \mathrm{~h}$. The control group was exposed to $1 \%$ ethanol or $1 \mathrm{mM}$ aqueous solution of Pluronic $\mathrm{F}$ 127. The cells were washed twice with phosphate buffer solution (PBS), fixed with $3.7 \%$ formaldehyde and washed again with phosphate buffer solution. Following the addition of Hoechst 33342 solution ( $1 \mu \mathrm{M}$ diluted with PBS) cells were incubated in a dark room at room temperature for $30 \mathrm{~min}$. After washing, they were examined under an immunofluorescence microscope at $465 \mathrm{~nm}$ (Olympus IX 81 model inverted microscope).

\subsubsection{Statistical analysis}

Data are reported as mean values $\pm \mathrm{SD}$. Experiments were repeated three times, with triplicate samples for each. Data were analyzed by Prism $6 \AA$ version 6.0d. Statistical significance was defined as $\mathrm{p}<0.05$.

To analyze the normality in the distribution of the data, the test "ShapiroWilk" was used. Statistical analysis of data with no normal distribution was performed using the non-parametric test of "Wilcoxon" with designed range.

\section{RESULTS AND DISCUSSION}

Extracts of different polarity were obtained from leaves and branches of L. rivularis and assayed against different human cancer cell lines: HT-29 colon cancer; PC-3 prostate cancer; MCF-7 breast cancer; and one non-tumor cell line, CCD $841 \mathrm{CoN}$ human colon epithelial cells $(\mathrm{CoN})$. The extracts were applied in homogeneous solution, using ethanol as solvent, or incorporated into polymer micelles of Pluronic F127.

The cytotoxicity of extracts in both forms, free and entrapped into polymer micelles, was evaluated in vitro by the sulforhodamine B colorimetric assay. The results obtained for different extract concentrations $(0-100 \mu \mathrm{g} / \mathrm{mL})$ with PC-3 cells are shown in Figure 2, whereas the $\mathrm{IC}_{50}$ values obtained for all cell lines are listed in Table 1 .

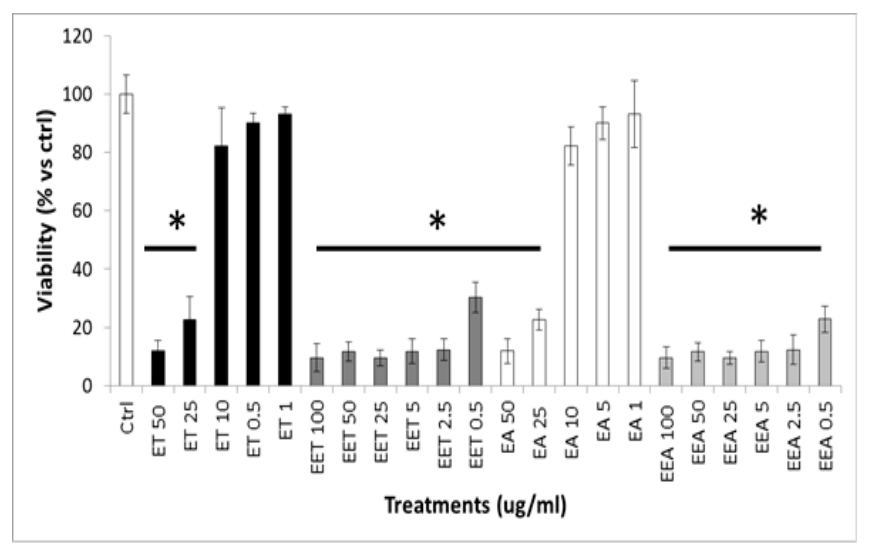

Figure 2. Effect of different extracts (entrapped or not) on cellular viability of PC-3 cells. Cells were exposed to different treatments (extracts free and entrapped form) at various concentrations $(\mu \mathrm{g} / \mathrm{mL})$. All data are reported as the percentage of viability in comparison with the vehicle-treated cells $(1 \%$ ethanol, Ctrl), which were arbitrarily assigned $100 \%$. ET ethanol extract; EET entrapped ethanol extract; EA, ethyl acetate extract; EEA entrapped ethyl acetate extract. ${ }^{*} \mathrm{p}<0.05$, significantly different from the vehicle-treated cells $(1 \%$ ethanol in medium, that is, compound concentration $=0$ ). 


\begin{tabular}{|c|c|c|c|c|c|}
\hline \multicolumn{6}{|c|}{$\mathrm{IC}_{50} \mu \mathrm{g} / \mathrm{mL}$} \\
\hline Cell line & EA & EEA & ET & EET & LTC \\
\hline HT-29 & $10.7 \pm 0.6$ & $0.05 \pm 0.01$ & $14.9 \pm 1.2$ & $6.7 \pm 1.4$ & $1.38 \pm 0.2$ \\
\hline MCF-7 & $12.0 \pm 0.4$ & $0.7 \pm 0.8$ & $11.8 \pm 0.4$ & $9.3 \pm 2.1$ & $1.12 \pm 0.3$ \\
\hline PC-3 & $10.7 \pm 0.9$ & $0.05 \pm 0.04$ & $15.6 \pm 1.8$ & $0.3 \pm 0.1$ & $1.63 \pm 0.3$ \\
\hline $\mathrm{CoN}$ & $>100$ & $2.5 \pm 0.3$ & $>100$ & $14.4 \pm 2.5$ & $1.88 \pm 0.3$ \\
\hline
\end{tabular}

Table 1. $\mathrm{IC}_{50}$ values $(\mu \mathrm{g} / \mathrm{mL})$ of $L$. rivularis extracts, in free and entrapped form, and free leptocarpin for different cancer cell lines and human colon epithelial cells. Data are reported as mean values \pm SD of three different experiments with samples in triplicate. ET ethanol extract; EET entrapped ethanol extract; EA, ethyl acetate extract; EEA entrapped ethyl acetate extract. Values of LTC are from Bosio et al. ${ }^{25}$

The effect of free and entrapped EA extract on PC-3 cells and nuclear morphology was analyzed by phase contrast and fluorescence microscopies, respectively (see Figure 3).
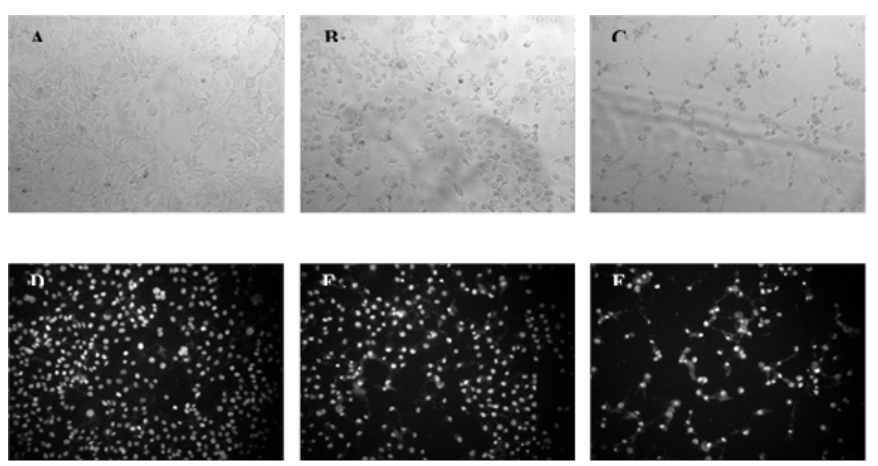

Figure 3. Effect of EtAcO extract on cellular and nuclear morphology of PC-3 cells. Representative photographs show cellular (a, b, c) and nuclear (d, e, f) morphologic changes observed by fluorescent microscopy of treated cells. Control: cells exposed to $1 \%$ ethanol $(a, d)$; cells treated with free $(b, e)$ and entrapped EtAcO extract (c, f) for $24 \mathrm{~h}$.

Representative images obtained with phase contrast microscopy of control cells (treated with $1 \%$ ethanol) and cells treated with EA and EEA extracts (25 $\mu \mathrm{g} / \mathrm{mL}$ ), are shown in Figures $3 \mathrm{~A}, 3 \mathrm{~B}$, and $3 \mathrm{C}$, respectively. These images show clearly that EA extract induces a size reduction and change in cell shape, and that this effect is much larger for the micelle entrapped extract.

On the other hand, the images obtained by fluorescence microscopy after Hoechst 33342 staining (Figures 3D-3F) show considerable nuclear fragmentation in treated cells. Comparison of images of cells treated with EA or EEA extracts (Figures $3 \mathrm{E}$ and $3 \mathrm{~F}$, respectively) indicate that the effect increases in presence of polymer micelles.

In homogeneous solution, at all tested concentrations, ET and EA extracts exhibit similar cytotoxicity with IC50 values in the range of $11-16 \mu \mathrm{g} / \mathrm{mL}$. These values are much lower than those needed to consider plant extracts as active ${ }^{46}$. Interestingly, the cytotoxicity of these extracts on normal cells is quite low $\mathrm{IC}_{50}$ $>100 \mu \mathrm{g} / \mathrm{mL}$, suggesting that these plant extracts act selectively on cancer cell lines. As discussed above, SQL exhibit cytotoxic activity against various cancer cell lines, and therefore the activity of these extracts must be related to their SQL content. In previous work, it has been found that L. rivularis contains a high percentage of SQL, and leptocarpin amounts to approximately $0.02 \%$ of the EA extract whereas the content of LTC in the ET extract is even lower ${ }^{23,24}$. To explain the origin of extract's activities the values of $\mathrm{IC}_{50}$ obtained for EA extract are compared with reported LTC cytotoxicity (last column in Table 1) and discussed as a function of LTC content. Considering the percentage of LTC in EA extract, the amount of LTC present at the highest $\mathrm{IC}_{50}$ measured for the EA extract $(15.6 \mu \mathrm{g} / \mathrm{mL}$ for PC-3) should be approximately $0.003 \mu \mathrm{g} / \mathrm{mL}$, which is 500 times lower than the $\mathrm{IC}_{50}$ of LTC (last column in Table 1). The amount of LTC decreases even more by decreasing the $\mathrm{IC}_{50}$ value. Thus, a comparison of $\mathrm{IC}_{50}$ values obtained for extracts with those reported for LTC (last column in Table 1) suggest that the activity of extracts is due to LTC and other secondary metabolites that are exerting a positive synergic effect. Among these are $8 \beta$-secbutyl leptocarpin; rivularin; $8 \beta$-angeloyl-1 $\beta, 3 \beta$-dihydroxy-4,10-dimethyl$\Delta 11$ (13) methylen-4Z,9Z-dienheliangol-6,12-olide (4); and $8 \beta$-angeloyl-1 $\beta, 3 \beta$ dihydroxy-4-methyl- $\Delta 11(13) \quad \Delta 10(14)$-dimethylen-4Z-enheliangol-6,12-olide (5). All these lactones were isolated from the EA extract, except for $\mathbf{4}$ and $\mathbf{5}$ that have been not isolated due to the low percentage in which they are present $t^{23,24}$ 47 .

On the other hand, incorporation of EA extract into polymer micelles enhances greatly the cytotoxicity against all cancer cell lines, the $\mathrm{IC}_{50}$ values of entrapped extracts are 20 to 200 times lower than those obtained with free extract; and 2 to 30 times lower than the respective values measured with LTC. These results clearly demonstrate the existence of an important effect of polymer micelles on the cytotoxicity, which could be attributed to an increase in biodisponibility or transport of active compounds into the cell. In addition, the even higher activity of entrapped EA extract, as compared to LTC, suggests that the synergic effect is enhanced by polymer micelles which selectively incorporate the most active compounds. For both extracts, the cytotoxicity against normal cells is also increased, and the $\mathrm{IC}_{50}$ values of entrapped extracts are in the range of $2.5-14.4 \mu \mathrm{g} / \mathrm{mL}$.

In previous work we have shown that LTC reduces cell viability by triggering apoptosis. Thus, in order to determine if the measured cytotoxicity of free and entrapped extracts is result of apoptotic process, the existence of induced changes in cell and nuclear morphology was assessed. Images obtained with phase contrast microscopy (Figure 3A-3C) show that cells with EA and EEA have lost their characteristic shape (appear as round mass) and are smaller in size, indicating a loss of cellular adhesion. Moreover, the number of cells is also reduced indicating a progression to cell death. Interestingly, the effect is more important in presence of Pluronic F 127. On the other hand, nuclear changes are also evident by fluorescence microscopy (Figures $3 \mathrm{E}-3 \mathrm{~F}$ ) and are enhanced by entrapping EA extract into polymer micelles. These results suggest the occurrence of apoptosis ${ }^{45}$, and are quite similar to those observed in the decreasing of cell viability induced by LTC on the same cancer cell lines ${ }^{25}$.

\section{CONCLUSIONS}

The cytotoxicity of ethyl acetate and ethanol extracts obtained from $L$. rivularis was evaluated against various cancer cell lines: PC-3 (prostate cancer), MCF-7 (breast cancer), HT-29 (colon cancer) and one non-tumoral cell line human colon epithelial cells $(\mathrm{CoN})$. The results indicate that both extracts exhibit activity on HT-29, MCF-7 and PC-3 cell lines, with $\mathrm{IC}_{50}$ values in the range of $11-16 \mu \mathrm{g} / \mathrm{mL}$. A comparison of these $\mathrm{IC}_{50}$ values with those previously reported for leptocarpin (last column in Table 1) suggests the existence of a synergic effect in the activity of EA extract. This effect can be attributed to the presence of other lactones that are minority components of this extract.

Interestingly, the cytotoxicity of both extracts is enhanced by physical entrapment into polymeric micelles formed by Pluronic F 127. This effect is especially important in the case of ethyl acetate extract, where the $\mathrm{IC}_{50}$ values are almost 200 times lower than those measured with its free form. These results suggest that polymer micelles enhance the apoptotic process induced by active non-polar components.

Finally, it is also noteworthy that neither of both extracts shows activity on non-tumoral cancer line, suggesting that extracts from L. rivularis act selectively on tumor cells. Thus, these extracts could be considered as an interesting target for future action in vivo studies. 


\section{REFERENCES}

1. A. J. Alonso-Castro, M. L. Villarreal, L. A. Salazar-Olivo, M. GomezSanchez, F. Dominguez, A. Garcia-Carranca. J. Ethnopharmacol. 133, 945 (2011).

2. J. L. Hartwell. Plants Used Against Cancer: A Survey. Quarterman, Lawrence, MA, USA (1982).

3. G. M. Cragg, P. G. Grothaus, D. J. Newman. Chem. Rev. 109, 3012 (2009).

4. M. Tascilar, F. A. De Jong, J. Verweij, R. S. Mathijssen. Oncologist. 11, 732 (2006).

5. C. Van Waes. Clin. Cancer Res. 13, 1076 (2007).

6. C. Van Waes, M. Yu, L. Nottingham, M. Karin. Clin. Cancer Res. 13, 4956 (2007).

7. A. S. Baldwin. J. Clin. Inv. 107, 241 (2001).

8. D. Basseres, A. Baldwin. Oncogene. 25, 6817 (2006).

9. A. Loercher, T. L. Lee, J. L. Ricker, A. Howard, J. Geoghegen, Z. Chen, J. B. Sunwoo, R. Sitcheran, E. Y. Chuang, J. B. Mitchell, A. S. Baldwin, C. Van Waes. Cancer Res. 64, 6511 (2004).

10. J. Wang, H. An, M. W. Mayo, A. S. Baldwin, W. G. Yarbrough. Cancer Cell. 12, 239 (2007).

11. S. P. Hehner, T. G. Hofmann, W. Droge, M. L. Schmitz. J. Immunol. 163, 5617 (1999).

12. T. H. Koo, J. H. Lee, Y. J. Park, Y. S. Hong, H. S. Kim, K. W. Kim, J. J. Lee. Planta Med. 67, 103 (2001).

13. M. T. Lindenmeyer, A. Hrenn, C. Kern, V. Castro, R. Murillo, S. Muller, S. Laufer, J. Schulte-Monting, B. Siedle, I. Merfort. Bioorganic Med. Chem. 14, 2487 (2006).

14. P. Rungeler, V. Castro, G. Mora, N. Goren, W. Vichnewski, H. L. Pahl, I. Merfort, T. J. Schmidt. Bioorganic Med. Chem. 7, 2343 (1999).

15. K.-Y. Lee, E.-S. Huang, C. Piantadosi, J. S. Pagano, T. A. Geissman. Cancer Res. 31, 1649 (1971).

16. P. Bremner, D. Rivera, M. A. Calzado, C. Obon, C. Inocencio, C. Beckwith, B. L. Fiebich, E. Munoz, M. Heinrich. J. Ethnopharmacol. 124, 295 (2009).

17. M. L. Guzman, L. Karnischky, X. J. Li, S. J. Neering, R. M. Rossi, C. T. Jordan. Blood. 104, 697A (2004).

18. M. L. Guzman, C. T. Jordan. Expert Opinion on Biological Therapy. 5, 1147 (2005).

19. C. J. Sweeney, S. Mehrotra, M. R. Sadaria, S. Kumar, N. H. Shortle, Y. Roman, C. Sheridan, R. A. Campbell, D. J. Murry, S. Badve, H. Nakshatri. Mol Cancer Ther. 4, 1004 (2005).

20. L. J. Zhao, Y. H. Xu, Y. Li. J. Dig. Dis. 10, 172 (2009).

21. D. Oka, K. Nishimura, M. Shiba, Y. Nakai, Y. Arai, M. Nakayama, H. Takayama, H. Inoue, A. Okuyama, N. Nonomura. Int. J. Cancer. 120, 2576 (2007).
22. J. Y. Cho, A. R. Kim, J. H. Jung, T. Chun, M. H. Rhee, E. S. Yoo. Eur. J. Pharmacol. 492, 85 (2004).

23. R. Martinez, B. Ayamante, J. A. Nunez-Alarcon, A. R. de Vivar. Phytochem. 18, 1527 (1979).

24. R. Martinez, V. Kesternich, E. Gutierrez, H. Dolz, H. Mansilla. Planta Med. 61, 188 (1995).

25. C. Bosio, G. Tomasoni, R. Martinez, A. F. Olea, H. Carrasco, J. Villena. Chem. Biol. Inter. 242, 415 (2015).

26. S. P. Hehner, M. Heinrich, P. M. Bork, M. Vogt, F. Ratter, V. Lehmann, K. Schulze-Osthoff, W. Droge, M. L. Schmitz. J. Biol. Chem. 273, 1288 (1998).

27. C. Wu, F. Chen, J. W. Rushing, X. Wang, H. J. Kim, G. Huang, V. HaleyZitlin, G. He. J. Med. Food. 9, 55 (2006).

28. P. M. Bork, M. L. Schmitz, M. Kuhnt, C. Escher, M. Heinrich. FEBS Letters. 402, 85 (1997).

29. Y. T. Tanaka, K. Tanaka, H. Kojima, T. Hamada, T. Masutani, M. Tsuboi, Y. Akao. Bioorg. Med. Chem. Lett. 23, 518 (2013).

30. S. Nasim, P. A. Crooks. Bioorg. Med. Chem. Lett. 18, 3870 (2008).

31. S. Neelakantan, S. Nasim, M. L. Guzman, C. T. Jordan, P. A. Crooks. Bioorg. Med. Chem. Lett. 19, 4346 (2009).

32. K. Kataoka, A. Harada, Y. Nagasaki. Adv. Drug Deliv. Rev. 47, 113 (2001).

33. N. Rapoport. Prog. Polym. Sci. 32, 962 (2007).

34. Y. Lu, K. Park. Int. J. Pharm. 453, 198 (2013).

35. Y. Matsumura, K. Kataoka. Cancer Sci. 100, 572 (2009).

36. R. Nagarajan. Colloids Surf., B. 16, 55 (1999).

37. P. Alexandridis, T. A. Hatton. Colloids Surf., A. 96, 1 (1995).

38. A. V. Kabanov, E. V. Batrakova, V. Y. Alakhov. J. Control. Release. 82, 189 (2002).

39. R. Basak, R. Bandyopadhyay. Langmuir. 29, 4350 (2013).

40. M. A. James-Smith, D. Shekhawat, B. M. Moudgil, D. O. Shah. Langmuir. 23, 1640 (2007).

41. M. Y. Kozlov, N. S. Melik-Nubarov, E. V. Batrakova, A. V. Kabanov. Macromolecules. 33, 3305 (2000).

42. A. F. Olea, H. Carrasco, L. Espinoza, B. Acevedo. J.Chil.Chem.Soc. 59, 2451 (2014).

43. T. Miller, G. van Colen, B. Sander, M. M. Golas, S. Uezguen, M. Weigandt, A. Goepferich. Pharm. Res. 30, 584 (2013).

44. V. Vichai, K. Kirtikara. Nat. Protoc. 1, 1112 (2006).

45. P. D. Allen, A. C. Newland. Apoptosis detection by DNA analysis, in Molecular Diagnosis of Cancer, F.E. Cotter, 16. Humana Press, New Jersey (1996).

46. M. Suffness, J. M. Pezzuto. Assays related to cancer drug discovery, in Methods in Plant Biochemistry: Assays for Bioactivity, K. Hosttetmann. Academic Press, London (1990).

47. B. Acevedo, F. Martinez, A. Olea. J. Chil. Chem.Soc. 58, 2038 (2013). 